\title{
Arguable Precedence for the World Wars of the Twentieth Century
}

\section{Radu Silaghi-Dumitrescu}

Babeș-Bolyai University, Cluj-Napoca

\begin{abstract}
With the largest number of casualties in human history, unprecedented planetary scale and documented cruelty, the two World Wars have marked the twentieth century as a time for extreme violence. Nevertheless, the casualties documented for wars across the past 2000 years equate to percentages of population in no way larger in the twentieth century. Arguably, the perception of the twentieth century as one of unprecedented violence is, beyond the obvious reality of the total number of victims, driven by an increased public awareness as a consequence of increased efficiency of information circulation. These observations are paralleled by others on human violence, but also on life expectancy, wealth, and technological advances such as those related to the efficiency of information trafficking - with typography proposed as an illustrative factor. Even so, with the exponential increase in population, any future world war (for, notably, no such conflict is precluded by the statistical trends discussed here, since the 2000-year trend has been relatively constant, slightly decreasing in recent years, but in no way reaching zero) would still be expected to entail death tolls larger than World War II.
\end{abstract}

The number of casualties in a war is generally taken as indication of the scale of the conflict; such statistics are nowadays commonly accessible and are discussed below (List of Wars... N.d.). The following text makes use of such numbers in order to give a short retrospective overview across the past $\sim 2000$ years.

\section{PARADIGM CHANGERS}

The World Wars of the twentieth century (WWI and WWII) are generally accepted as paradigm changers, from points of view that include being the bloodiest as well as some of the cruellest (with the Holocaust as most obvious manifestation) in human history. The twentieth century itself may then be noted to have brought the largest number of war casualties in human Social Evolution \& History, Vol. 17 No. 2, September 2018 96-108 
history. Other points of view include the scale of financial and technological progress - including mass destruction weapons such as the nerve gases of WWI or the atomic bombs of WWII.

Occasionally, other wars are also mentioned as paradigm changers or as particularly gruesome; the civil war in the USA, the Napoleonic wars, the Mongol invasions, the fall of Byzantium, and others. Nevertheless, there is indeed no precedent for the (minimal) estimates of 20 million for WWI and 40 million for WWII, and for the total of (minimal estimates) 73 million deaths in the major wars of the twentieth century (taking into account such events as WWI, WWII, the Mexican war, the Spanish civil war, Korea, Vietnam, persecutions on German ethnics after WWII, the Iran-Iraq war, Afghanistan, and Cambodia). Assuming an average population of four billion people for the century, these casualties would amount to 1.8 per cent of the total population, or roughly 0.018 per cent of the world population killed on average each year during the twentieth century.

Arguments may, however, be found to support the concept that the twentieth century wars were neither the cruellest, nor the bloodiest of human history - even though they are so perceived. 'Perceived' is indeed the key word in this line of reasoning, since the major paradigm change that we argue to have defined these wars is not their death toll but the public awareness thereof. It may be argued that while humans continued to slaughter themselves at rates similar and with cruelty not unlike those seen throughout their history, the twentieth century saw a marked increase in the awareness on this topic, and in the ethical and moral questions asked. While the wars were uniting across the globe to create 'world wars', so was public opinion and social conscience.

$\sim 50$ BCE: Gallic wars

Gallic wars alone are estimated to have brought (58-50 BCE) 0.7 million casualties, at a time when the world population was estimated at 200 million. At a time scale similar to World War I, the Gallic Wars were wiping away 0.4 per cent of the world population as opposed to the 1.12 per cent of WWI. It is easy to assume that the remainder of the world would, at that same time, provide further casualties to closely match the relative rates seen 2000 years later in WWI.

\section{$\sim 200$ CE: War of the Three Kingdoms, China}

Lower estimates for the casualties of the events generally known under this name are cited at 36 million between the years 184 and 280. This includes wars, rebellions, but also plundering and ensuing famine. Accounts are gruesome and in no way weaker than those surrounding the twentieth century Nazi war crimes, for instance. With a total world population estimated at that time at 200-260 million, the War of the Three Kingdoms alone seems to have wiped away 14 per cent of the world population. Other 
places - from India to Africa, Europe and the Americas, were oblivious to this carnage and pursuing their own wars, so that the world total of war casualties for that particularly century was likely much higher than the average of 0.15 per cent of the world population per year.

As the casualties of this Chinese war are counted based on census documents, and as these documents are thought to have been incomplete, chances are that the 36 million figure is a significant overestimate. However, even if overestimated by one order of magnitude, it would still lead to the same percentage of casualties (per total population) as those from the cumulated wars of the twentieth century.

400 CE: Fall of Rome

The events leading to the fall of Rome (395-455) are proposed to have involved 7 million casualties alone in Europe. With a world population still at 200 million, this would imply 3 per cent of the world population - a relative rate higher than what Europe and the world were seeing later, in the twentieth century.

\section{0-1400: Mongol conquests}

Between 1206 and 1386, a total of 30 million people are thought to have fallen victims of these wars. This represents $\sim 7$ per cent of the world population at that stage (300-450 million), or roughly 0.04 per cent of the world population killed each year - which is double the rate seen in the twentieth century.

This period also partly superimposes with the 1095-1291 duration of the European-led Crusade wars, thought to have caused at least one million victims. In this context, indeed the thirteenth century may be judged to have been distinctly more destructive than the twentieth.

1400: Timurid conquests, the Hundred Years' war

From 1337 to 1453 the Hundred Years' war in Europe took 2 million lives, approximately 0.5 per cent of the total world population. On the other hand, the Mongol conquests of the Timurid dynasty between 1369 and 1405 took 15 million lives - i.e. 4.0 per cent of the world population estimated at 380 million.

1600: French wars of religion, Qing dynasty, Russia, 30 Years' war

Between 1562 and 1598 the French wars of religion took two million lives in a limited part of Europe alone, i.e. 0.4 per cent of the total world population and with a rate of 20 times higher than that seen throughout the twentieth century.

Between 1616 and 1662 the Qing dynasty conquest of the Ming dynasty is thought to have involved 25 million casualties - roughly five per cent of the world population. Even if overestimated, it remains with a relative rate of death higher than WWII. 
In Russia, five million people are estimated to have been lost in wars between 1598 and 1613 - roughly one percent of the respective world population.

With 3.3 million victims, the European Thirty Years' war (16181648) would have claimed 0.6 per cent of the world population of just over 500 million.

The nineteenth century

The nineteenth century saw a streak of large-scale bloodsheds, from the Napoleonic wars (1803-1815 throughout the world, 3.5 million, 0.4 per cent of world population) to the Ndwandwe-Zulu War in Africa (18161828, 1.5 million, 0.1 per cent), the Taiping rebellion in China (18511864, 20 million, 1.6 per cent), the Mahdi-related Sudan wars (1881-1898, 5.5 million, 0.4 per cent), as well as the Paraguayan war (1864-1870), the Circassian genocide (1864-1867), the USA civil war (1861-1865) and the Du Wenxiu Rebellion in China (1856-1873) which altogether totalled 2.1 million further victims. Between just these more notable wars, the total of 32.6 million victims represents 3 per cent of the average world population - or a rate of 0.03 per cent of the population killed per year, which is distinctly higher than what the twentieth century had to offer.

\section{COMPARISONS IN RATES}

It may be argued, with the above numerical data, that in terms of relative percentages in victims, the twentieth century was not much different from many previous ones. The notable increase in absolute numbers of casualties, and the notable worldwide characters of wars, may be seen as a result of the exponential increase in world population as opposed to being due to any increase in the general tendency towards violence. Fig. 1 illustrates this evolution. Up until $\sim 1600$ the world population as well as the percentage of casualties in major wars follow similar trends, and show at most a slight increase (other sources show data going as far as back as year $500 \mathrm{BCE}$, with the same constant trends). By contrast, the nineteenth and twentieth centuries see the two trends oppose each other: while the total world population soars exponentially, the percentage killed in major wars shows a small decrease.

Violence and cruelty in the twentieth century wars - from the use of mass destruction weapons to the Nazi Holocaust or to the Ukrainian famine in the USSR - are also entirely with precedent in time. Beyond many famines, cruel punishments such as scalping, impaling, boiling alive, crucifixions, cutting in pieces, feeding to animals, burning alive, mass beheadings, violent ethnic cleansing, mutilation and other practices are recorded throughout human history and leave the likes of Auschwitz with no novelty other than the increase in absolute size - but not in terms of per- 
centages of total human population submitted to abuse. To illustrate this, in 1462 the following report was being addressed officially to Pope Pius II, and caused positive reactions and celebrations in various European courts - from the Hungarian kingdom to the Italian states: 'I have killed peasants men and women, old and young, who lived at Oblucitza and Novoselo, where the Danube flows into the sea... We killed 23,884 Turks without counting those whom we burned in homes or the Turks whose heads were cut by our soldiers' (Lallanilla 2013). By contrast, almost 500 years later another Pope Pius (this time Pius XII), was protesting publicly against the fact that during WWII 'hundreds of thousands of persons who, without any fault on their part, sometimes only because of their nationality or race, have been consigned to death or slow extermination' (Pope Pius XII's 1942... N.d.).

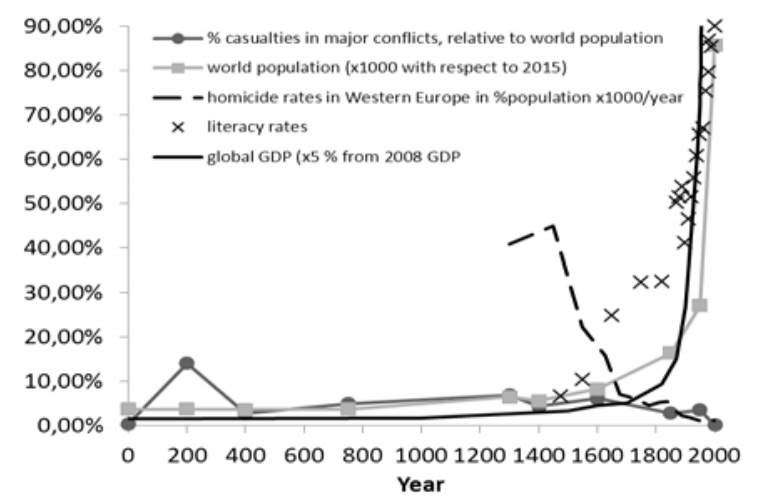

Fig. 1. Percentages of world population killed in major wars over the past 2000 years (based on data from List of Wars... N.d.), taking into account the lower estimates of casualties for each war), evolution of the world population itself (data from World Population... N.d.), the rate of homicides in regions of Western Europe (simple average on data concerning England, Netherlands, Belgium, Scandinavia, Germany, Switzerland, Italy, taken from Roser 2016a), literacy rates

(simple average of data listed for Netherlands, Great Britain, Sweden, Germany, France, Italy, Ireland, Belgium, Spain, Poland, Russia,

USA, Chile, Brazil, Argentina, Mexico, Peru taken from Roser 2016b) and global GDP (sums of values listed for individual continents and/or economic spheres in Roser and Nagdy 2016, and Maddison 2011). Data are plotted at the middle of the corresponding time range (e.g., 1850 for data concerning the entire nineteenth century)

The above observations are in line with more general observations on human violence. Figure 1 illustrates this point with data on homicide rates in parts of Western Europe: while 1600 saw the beginning of a decrease 
in the percentage of human population killed in wars, it also marks the beginning of an abrupt decrease in homicide rates until the nineteenth century, and a slower decreasing trend until the present times (now much closer to zero, from the 40 victims per 100,000 inhabitants of 1300). Also related to the above data, Pinker points out that the late 1700s also coincide with an accelerated trend in the abolition of judicial torture and in abolition of slavery - i.e., other forms of societal violence (Pinker 2011). We thus note that others have also pointed towards a decline in individual violence throughout history, and a lack of increase in general societal violence - as manifested in, for example, war casualties. In fact, it was previously commented that while "the deadliest "multicides" are more plentiful in recent centuries', 'killings as a percentage of all humanity are probably declining' (Cohen et al. 2011). Figure 1 now gives a quantitative confirmation to this hypothesis. The data is consistent with other representations (e.g., Christian 2004), while other authors have presented a more limited set of data, only from $\sim 1500$ and in which only battle-related deaths of 'great powers' are listed, where the trend appears to feature a sharp unprecedented rise caused by WWI and WWII, preceded by, and followed by, relatively steady and much lower rates (Levy and Thompson 2011).

If the relative prevalence and the nature of the war-related violence has not increased significantly throughout history (as seen above, they may have decreased), the public perception of these acts has clearly changed dramatically. Widespread literacy, combined with huge increases in information trafficking (due to technical reasons as well as to larger populations), imply that today any notable act of violence receives immediate attention worldwide. Such public awareness is doubled by a much tighter moral scrutiny. Most countries no longer tolerate torture, or ethnically - or racially-driven violence, or random violence. There is, additionally, a much tighter rule of international law that limits war-like conflicts - all of which is at least partly based on moral concerns raised by citizens. In this context the twentieth century military conflicts, because of their spatial and temporary proximity to a much larger body of much better educated people, would have been inevitably perceived in a very negative way - beyond the fact that in terms of absolute numbers the casualties were also more than those of previous, more local, wars. These considerations are in agreement with those previously formulated based on numerical data. Figure 1, for instance, shows that for approximately the same cultural area the drastic decline in homicide rates coincides with the beginning of a notable increase in literacy rates. Many argue that literacy and moral standards are directly correlated; Pinker for instance quotes Voltaire's 'qui est en droit de vous rendre absurde est en droit de vous rendre injuste', arguing that literacy allows for an increase in cosmopoli- 
tanism and for more time allocated for increasingly complex reasoning. While the counter-example of mass manipulation in recent totalitarian regimes may be given against Pinker's arguments, it is difficult to find arguments against the thesis that the wider-spread access to written (and, later on, audio-visual) information does allow for more informed citizens and administrators, thereby limiting the input of incomplete/inefficient communication into the escalation of any potential conflict and increasing the opportunities for organized peaceful (and increasingly democratic) solutions. Pinker explicitly shows that the rise in literacy correlates with a rise in the efficiency of book production - and is thus another effect of technological advance (Pinker 2011). Under this line of reasoning, information technology in the very broad sense was the driving force for the distinct decrease in human violence. Pinker further argues that larger administrative aggregates (states) and more extended trade have additionally contributed to the decrease in violence (Pinker 2011); these may also be linked to the increase in global GDP, which ( $c f$. Fig. 1) mirrors very closely the rise in world population and hence correlates negatively with global violence with ensuing correlations with the rest of the factors discussed here. Arguably, the technological advances, and especially those in information technology, are the ones that allow more solid and complex trade links, and more intricate and controllable administration systems. Prior to Pinker, Nazaretyan in fact had proposed mathematical formulae (the "bloodshed ratio' and variations thereof) for describing and comparing data similar to the ones discussed in Fig. 1 for war casualties across history; moreover, Nazaretyan explicitly proposed a 'law of techno-humanitarian balance' (hereafter denoted LTHB) according to which 'the higher the power of production and war technologies, the more advanced behavior-restraint is required to enable the self-preservation of society' (Nazaretyan 2009: 102-132). Since LTHB mirrors (or may be derived from) simple equilibria principles in physical/chemical/biological systems, no reasonable counter-arguments are likely to be found. On the other hand, underlying both the power of production of war technologies and the social mechanisms of restraint, one may arguably find, from one end to another, precisely the efficiency of information trafficking (exponentially increasing, as Nazaretyan puts it, as a 'a trend, which started with the first artificial sign systems and then steadily developed' (Idem 2010: 22-36). Others have elaborated on, for example, how the modern information technology, via its 'virtualization of violence', has affected and may further affect/modulate societal violence with beneficial effects within a paradigm wherein violence is an anthropological constant (Ibid.: 22-36).

Biological factors have also been invoked as possible reasons behind the decrease in violence. The last two centuries have indeed seen a sudden rise in IQ (Crepin 2009: 9-12) but this may be argued to be a mere effect 
of wider literacy (implying general improvements in all areas of education). One may in fact question to which extent the same increase in literacy, by allowing for educating/instructing more higher-qualified people physicians and health administrators included - may have caused the life expectancy to rise significantly as of the nineteenth century after many centuries of $\sim 35$ year-values. Perhaps interestingly, a good part of this rise has been due to drastic decreases in child mortality (below five years) and exponentially so from the end of the nineteenth century - with a parallel decrease in maternal mortality at birth (Roser 2016c). These relatively sudden changes may be argued to have fuelled human society with a set of individuals who according to simplistic evolutionism ('survival of the fittest in the wild') would have no relevant chance of existence and no relevant impact on their species - but who precisely due to the evolutionary advantage brought about by technology have, for the past 200 years, been contributing remarkably to the size of population - not because their parents were running faster or eating more, but rather because their peers and their societies (which, if read as countries, may mean millions to hundreds of millions) had further advanced technologically. This would come with obvious consequences in terms of enrichment of genetic populations - the effects of which may be too soon to consider. On the biological side, two other aspects may need consideration as previously pointed out (Nazaretyan 2010: 22-36). First, that the negative emotions and violence are embedded in our biological constructs - and that, hence, it is for now impossible to escape our intrinsic need for violence. Second, that a man-machine fusion may offer a route towards evolving beyond our violence-dependent biological limitations. As negative emotions in general may in principle be reduced to basic needs of control over one's habitat, (hence pervasive and intrinsic to biological systems), it is intuitive that such 'control' can only be certain when the competitor is either obliterated or entirely submissive - hence the violence. War-like conflicts are pervasive between and within species, in more or less subtle ways: from subtle invisible ways at inter-cellular level such as hormones and toxins, to World War II - the differences are merely in format and efficiency, not in principles. As such, physical aggression, in its anthropological/historical sense, may well be a simple temporary tool for social interaction, towards a future where habitat control may be fought for with tools that may prove more efficient (and not necessarily less cruel) than those that have shaped our history so far. Efficiency indeed, understood as a productive gathering and processing of information, may be argued, as stated above, to be a key driver of all phenomena illustrated in Fig. 1. 


\section{PREDICTIONS FOR THE FUTURE}

The exponential increases in population and in general technological advances have previously prompted a logical conclusion - that in a few decades a 'singularity' would be reached, where progress (especially on the technological side) would increase at near-infinite rates. The singularity then offers two possible scenarios, both catastrophic to the current nature of the human species: either a (quasi) self-destruction, or an unprecedented moment of evolution. However, Nazaretyan's cited LTHB also offers ground for further discussion, in conjunction with the realization, not obvious from Fig. 1 but entirely established from numbers spread in more detail especially over the past $\sim 200$ years, that human societies display oscillatory behaviour - i.e., the so-called 'cycles' or 'waves' (e.g., Kondratieff waves, Juglar cycles, Kitchin cycles etc.) (Grinin, Korotayev, and Tausch 2016: 55-109; Nazaretyan 2015: 755).

As discussed above, violence has been more or less an anthropological constant; indeed, the normalized number of war-related casualties in Fig. 1 may be approximated as a relatively horizontal line across the historical data analysed here. The availability of more precise data for the more recent years, while tempting, offers the great risk of overspeculation by lending excessive weight to data gathered over an excessively small portion of the x-axis. Such over-speculations have led to stances claiming that a third World War would be impossible because humans have already evolved biologically towards a less violent species, or to stances claiming that, on the contrary, the nineteenth century is testament to an evolution of humans into a more violent species (Nazaretyan 2015: 755). Instead, we propose that Fig. 1 is a mere confirmation of Nazaretyan's LTHB, and that if extrapolation is attempted then hundreds of millions of war-related deaths in the twenty-first century may be anticipated. The uneven spread of data over the 2000 years does mean that any speculation as to the exact date of a next major World War (or even as to the possibility of a World War as opposed to a flurry of localized conflicts) would be entirely unsupported by the data in Fig. 1.

On the other hand, the numbers in population, GDP or literacy follow an entirely different trend - one that at first sight is positive but at second sight is reason for concern due to the seemingly unavoidable upcoming singularity or, more generally, to an accelerating non-equilibrium between technological advances and the social mechanisms available for regulation and control over those advances (Nazaretyan 2015: 755). On this we may present as a caveat Fig. 2, illustrating the estimated GDP for the world (as in Fig. 1) but now also for separate regions of the world. It may be seen that while the world on average/total seems to have seen stagnation from antiquity to the year $\sim 1000$, and then a steady increase to 1800 , the various regions of the world (for a good part of the respective time interval 
acting as separate markets) have witnessed widely different evolutions. Thus, at a time when Western Europe saw a dramatic decrease, Western Asia was seeing entirely the opposite trend, while other regions (Africa, Latin America, Eastern Europe) were much steadier. Even within Western Europe, one needs to point out that the decrease in GDP singularly reflects the fall off Rome; in fact, of the 12 Western Europe territories that make up the contribution seen in Fig. 2, only Italy saw a dramatic decrease between the years 0 and 1000, with a drop by $\sim 50$ per cent of the GDP taking it to values close to those seen in the other territories (Germany, UK, Belgium etc.), where, however, the GDP remained roughly constant during this time. Then, from 1000 to 1800 Europe sees a distinctive increase in GDP, accompanied slowly by Latin America, while Asia and Africa see entirely different trends. Thus, what at 'world-average' may have appeared a smooth (albeit with cycles/waves) transition towards progress, turns out to be composed of drastically different components of apparent progress and regress, in areas relatively independent/separated from each other.

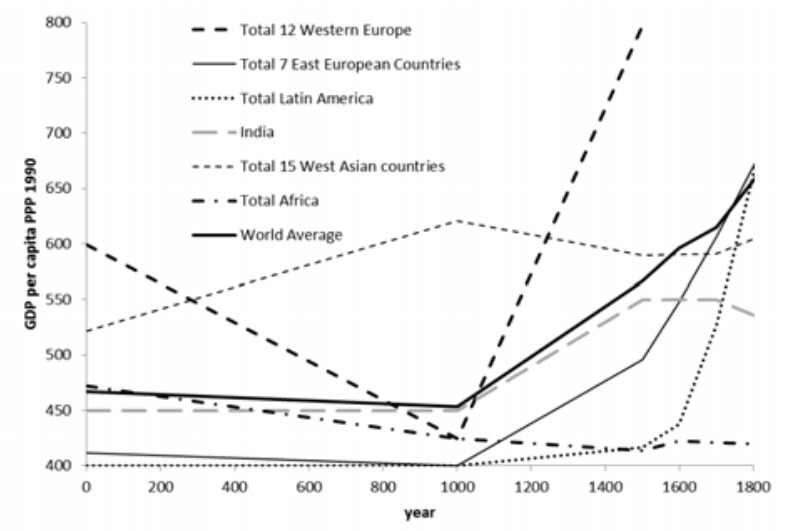

Fig. 2. Same data as in Fig. 1 for world GDP, now also detailed for six different regions of the world, up until the year 1800

In this context, Fig. 3 illustrates recent trends in population, detailing the data already shown in Fig. 1. Beyond the well-known exponential increase in world population, one may note distinctly different trends between various regions: while China is a major contributor to the worldlevel trend, the older members of the club or rich nations, such as Germany, Italy, or Japan, appear to have now for decades stalled their population numbers. Notably, it is such countries as these latter three that are also important drivers towards technological development. One may then reasonably speculate on a scenario where the world's emerging economies 
would each in its time reach similar plateaus as Italy or Germany or Japan, as some form of equilibrium is indeed reached between technological advances and societal regulatory advances. If so, then this may be taken as evidence for mechanisms apt to avoid the singularity - though the caveat remains on the cyclic/wave-like character that would dominate behaviour on such shorter time scales. Last but not least, none of the GDP/population/war-casualty data for the past 2000 years has any use in accurately predicting the on/off behaviour of a global system where instant global apocalypse is at the fingertips of a few individuals. If or when one would speculate, using LTHB as argument, that societal controls have or will be found in order to safely avoid self-extinction, one is still left with the fact that today's rates and amplitudes of information trafficking and of response to external and societal stimuli are so drastically different than those of any other past event, that any numerical prediction for the medium-term future faces at least significant methodological challenges.

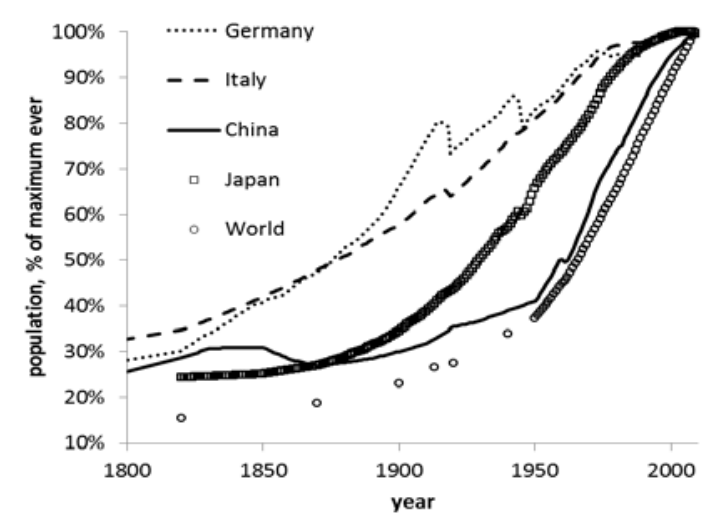

Fig. 3. Same data as in Fig. 1 for world population, now detailed for four different countries of the world, 1800-2008

To conclude, while the size of the damage, the technology involved, and the political effects of WWI and WWII qualify them to be considered paradigm-changers, it may be argued that counteracting all of these factors was a change in information management and in education, which would drive people to ask different/new things from their representatives and rulers, and to perceive in a changing manner any act of war and especially its negative connotations. These observations match previous ones on a range of parameters related to violence, literacy, health, wealth, and going as far as the efficiency of book production. In agreement with considerations exposed by Nazaretyan (Nazaretyan 2010: 22-36), acute perception of military violence is thus argued to be not a symptom of some acute increase in such violence, but rather a contributing factor towards 
an eventual decrease, fuelled by an increase in the magnitude and efficiency of information trafficking in human society. The relatively steady level of normalized war-related casualties (bloodshed ratio) over the past 2,000 years, even if with a slight decrease over the past few decades, cannot be taken as mathematical evidence that wars and violence would stop any time soon (or that there would be significantly less victims), nor that humans have become more violent.

\section{REFERENCES}

Christian, D. 2004. Maps of Time: An Introduction to Big History. Berkeley: University of California Press.

Cohen, M., Ericson, M., Marsh, B., and Quealy, K. 2011. Population Control, Marauder Style. URL: http://www.nytimes.com/imagepages/2011/11/06/ opinion/06atrocities_timeline.html.

Crepin, H. 2009. L'effet Flynn. URL: http://commons.wikimedia.org/ wiki/File:Qi_histoire.jpg. 8: 9-12.

Grinin, L., Korotayev, A., and Tausch, A. 2016. Interaction between Kondratieff Waves and Juglar Cycles. In Grinin, L., Korotayev, A., and Tausch, A. (eds.), Economic Cycles, Crises, and the Global Periphery (pp. 55-109). Springer.

Lallanilla, M. 2013. Meet Vlad The Impaler, The Bloodthirsty Ruler Behind The Dracula Legend. Huffington Post.

Levy, J. S., and Thompson, W. R. 2011. The Arc of War: Origins, Escalation and Transformation. Chicago: University of Chicago Press.

List of Wars and Anthropogenic Disasters by Death Toll. N.d. Wikipedia. URL: http://en.wikipedia.org/wiki/List_of_wars_and_anthropogenic disasters_by_death_toll.

Maddison, A. 2011. Statistics on World Population, GDP and Per Capita GDP, 1-2008 A.D. URL:http://www.ggdc.net/maddison/oriindex.htm.

Nazaretyan, A. P. 2009. Technology, Psychology and Catastrophes: On the Evolution of Non-Violence in Human History. Social Evolution \& History 8: $102-132$.

Nazaretyan, A. P. 2010. Virtualization of Social Violence: A Sign of our Époque? Societal and Political Psychology International Review 1: 22-36.

Nazaretyan, A. P. 2015. Peering into the $21^{\text {st }}$ Century: Mega-History and its 'Mysterious Singularity'. Vestnik Rossiyskoy Akademii Nauk 85: 755. Original in Russian (Назаретян А. П. Мегаистория и её 'загадочная сингулярность'. Вестник Российской академии наук 85: 755).

Pinker, S. 2011. A History of Violence: Edge Master Class 2011. Edge.org, September 27. URL: https://www.edge.org/conversation/mc2011-historyviolence-pinker. 
108 Social Evolution \& History / September 2018

Pope Pius XII's 1942 Christmas Address. N.d. Wikipedia. URL: https://en. wikipedia.org/wiki/Pope_Pius_XII\%27s_1942_Christmas_address.

Roser, M. 2016a. Homicides. URL: https://ourworldindata.org/homici des/.

Roser, M. 2016b. The Visual History of Decreasing War and Violence. URL: http://ourworldindata.org/VisualHistoryOf/Violence.html\#/8.

Roser, M. 2016c. The Visual History of Global Health. URL: http://our worldindata.org/VisualHistoryOf/Health.html\#/Child-Mortality-def.

Roser, M., and Nagdy, M. 2016. Economic Growth. URL: https://our worldindata.org/economic-growth.

World Population Estimates. N.d. Wikipedia. URL: https://en.wikipedia.org/ wiki/World_population_estimates. 